\title{
LOS CONVITES: TERTULIAS MUSICALES EN LOS OASIS DE PICA Y MATILLA, NORTE DE CHILE*
}

\author{
FEASTS: MUSICAL GATHERINGS IN OASES OF PICA AND MATILLA, \\ NORTH OF CHILE
}

\author{
Jean Franco Daponte ${ }^{* *}$ y Tiziana Palmiero ${ }^{* * *}$
}

\begin{abstract}
En Pica y Matilla, dos pequeños oasis ubicados en la región de Tarapacá, norte de Chile, se realizaron, hasta la década de 1970, los convites: tertulias familiares con música y baile. Según cuentan sus últimos protagonistas, el formato de estas fiestas es heredero de las reuniones que se efectuaban ya desde el siglo XIX, periodo que coincide con el desarrollo de las oficinas salitreras en la región. La explotación del mineral involucró de diferentes maneras a los pobladores de los oasis precordilleranos y cambió sus economías y costumbres. Los convites duraban un día entero y ocupaban diferentes espacios como la chacra (pequeñas huertas), el salón y las calles del pueblo. A partir de fotografías, videos, grabaciones musicales, partituras y entrevistas realizadas a los últimos protagonistas de estas celebraciones, se analizan los convites en sus aspectos espaciales, sociales y musicales, vinculándolos con los acontecimientos políticos y culturales del período.
\end{abstract}

Palabras claves: Cultura tarapaqueña, tertulia, oasis de Pica y Matilla, cachimbo, cueca.

In Pica and Matilla, two small oases located in the region of Tarapaca, north of Chile, were carried out until the 1970s, the "convites": family gatherings with music and dance. According to the last protagonists, these parties' format is an inheritance of the gatherings held since the 19th century, a period that coincides with the development of the saltpeter offices in the region. The exploitation of the mineral involved the pre-Cordilleran oases' inhabitants in multiple ways and changed their economies and customs. The convites lasted a whole day and took place in different spaces such as the chacra (small farm), the hall, and the town's streets. Based on photographs, videos, musical recordings, scores, and interviews made to the last protagonists of these celebrations, the convites are analyzed in their spatial, social, and musical aspects, linking them with the period's political and cultural events.

Key words: Tarapacá Culture, gathering, Pica, and Matilla oases, cachimbo, cueca.

\section{Introducción}

Los convites fueron tertulias de carácter familiar que se realizaron en los oasis de Pica y Matilla, entre el siglo XIX y el siglo XX. La memoria histórica de los protagonistas de los convites nos remite a un período anterior al 1900; de hecho, en una entrevista realizada en 1994, el músico y escritor piqueño Enrique Luza contaba haber obtenido información de este tipo de festejos por una "sobreviviente de avanzada edad en 1945" de la "casa de la familia Bermúdez” (Luza 1996:79) ${ }^{1}$. Por lo que es probable que el recuerdo de esta "sobreviviente" se remonte a la segunda mitad del siglo XIX. Los convites se practicaron con pleno vigor durante la primera mitad del siglo XX, para decaer paulatinamente durante la década de 1970; fecha que coincide con el inicio de la dictadura de Pinochet, la que marcó profundamente la vida social, económica y cultural de la región. En la actualidad se asiste a un deseo de reestablecer la usanza de los antiguos convites, con sus comidas, cantos y danzas.

En cuanto a su estructura, estas tertulias se desarrollaban en distintos espacios y duraban un día entero. Los festejos comenzaban en las chacras por las mañanas y culminaban por las noches en uno de los salones del pueblo; además, durante los desplazamientos de la comitiva, los cantos inundaban los callejones de las chacras y las calles del pueblo. Para la ocasión, los asistentes preparaban comidas y bebidas tradicionales; se degustaban los vinos locales y una gran variedad de cócteles fabricados con aguardiente y saborizados con las frutas de las huertas. En las chacras, los más jóvenes y niños, se bañaban en los canales de regadío, mientras los adultos bailaban cuecas y valses populares y cantaban los nostálgicos yaravíes, acompañados por guitarra, mandolina, violín y bombo. Al atardecer,

\footnotetext{
* Resultado de los proyectos: FONDECYT, 1181844 y Fondo de la Música Nacional 2015, 71335.

** Universidad de Tarapacá, Departamento de Educación. Arica, Chile. Correo electrónico: jdapontea@academicos.uta.cl

*** Universidad de Tarapacá. Arica, Chile. Correo electrónico: tizianapal@ hotmail.com
} 
los contertulios se dirigían en un festivo pasacalle hacia la casa del anfitrión o de algún invitado que tuviera un salón amplio y un piano; allí se escuchaban yaravíes y tonadas y se bailaban las contradanzas y el cachimbo hasta el amanecer, momento en que los invitados regresaban a sus hogares interpretando otro ruidoso pasacalle.

La tertulia salonera, así como los paseos en el campo, en que la música cumplía un rol de diversión y también identitario, fue común en varios países latinoamericanos que, al comenzar la etapa republicana, experimentaron la exaltación de las ideas burguesas propias de las nuevas naciones (Claro 1997: Martínez y Palmiero 2000). Los textos de los cantos y bailes que, en la mitad del siglo XX se interpretaban todavía en Pica y Matilla, se hacían eco de los valores de la burguesía republicana; en los textos se habla del amor, de la naturaleza generosa y del apego al territorio; se recuerda, a veces con nostalgia, al pasado peruano y no faltan las referencias a importantes hechos políticos, como lo fue la Guerra del Pacífico que, desde 1883, con la incorporación de la región a la administración chilena, decidió el futuro de estos pueblos.

Nuestra hipótesis es que las características de los convites y su funcionalidad se definieron en los oasis en la mitad del siglo XIX, en un momento particular de la historia de la región, que coincide con el desarrollo de la explotación del salitre (aprox. 1850-1960). Este hecho no es de extrañar, ya que la minería salitrera, que contaba con capitales extranjeros, especialmente ingleses, significó una modernización de todos los sectores involucrados: desde la agricultura hasta la mano de obra y el transporte. La presencia de familias adineradas europeas facilitó seguramente la incorporación, en las tertulias, de las danzas centroeuropeas y del piano; sin embargo, la fuerte identidad campesina y el apego a las tradiciones, típica de los pueblos periféricos, como lo son Pica y Matilla, se reflejaba en la sobrevivencia de bailes criollos y "de la tierra" por buena parte del siglo XX. Además, la especial conformación urbanística del pueblo -que incorpora las chacras a la vida familiar, como una extensión del hogar-favoreció un tipo de celebración que se desarrollaba en cuatro espacios distintos y la existencia de repertorios específicos para cada uno de estos.

Los trabajos musicológicos desarrollados en la región de Tarapacá son escasos; se trata, en su mayoría, de investigaciones históricas y sociológicas acerca de la fiesta de la Virgen del Carmen de la Tirana ${ }^{2}$, que tocan a los aspectos musicales de manera tangencial. Sin embargo, destacamos los trabajos relacionados con las asociaciones de bailes religiosos (Kessel 1987; Henríquez 1996; Díaz 2011); algunos estudios que enmarcan la danza y la religiosidad popular en los procesos históricos y culturales de la región (Uribe Echeverría 1973; Núñez 2004; Díaz y Lanas 2015). Respecto de estudios específicos acerca de música y danzas tradicionales en Pica y Matilla, contamos con una etnografía de las principales fiestas religiosas del oasis con especial énfasis en la artesanía local (Platt 1968); un estudio que recopila y analiza las formas coreográficas y musicales del cachimbo (Loyola 1994) y una compilación de partituras y escritos de las tradiciones culturales de los oasis (Luza 1996). A estos hay que agregar los trabajos más recientes referidos a las manifestaciones musicales de los oasis: análisis musical del cachimbo y su relación con algunas tonadas del siglo XVIII (Daponte 2006 y 2010); aportes de la cultura de los afrodescendientes a la música de los oasis (Daponte 2010 y 2019); contamos también con un exhaustivo informe del desarrollo histórico y las características de la danza del cachimbo en la región (Díaz y Daponte 2017).

En cuanto a las fuentes utilizadas, para el estudio del repertorio de los convites que se realizaban entre finales del siglo XIX y primera mitad del siglo XX, nos basamos en algunas partituras conservadas en los archivos personales, pocos instrumentos musicales, valiosas grabaciones de danzas y cantos, y entrevistas a los últimos cultores de estas reuniones festivas, realizadas entre 1994 y $2004^{3}$, cuyos recuerdos se remontaban a aquella época. Además de dos fuentes escritas que se refieren a hechos ocurridos en 1884, en Pica y en el Tamarugal, que estarían relacionados con los convites. La metodología se basa principalmente en análisis de fuentes primarias y secundarias; trabajo de campo realizado entre 1994 y 2014, además de los recuerdos de la familia de Jean Franco Daponte y de su experiencia en calidad de investigador insider; transcripciones y análisis de material musical. En ocasión de esta investigación, los autores del presente artículo han participado en las actuales tertulias organizadas por los clubes de cachimbo, integrados por músicos y bailarines de los oasis ${ }^{4}$. 


\section{Desarrollo del convite en el contexto político y cultural de la región de Tarapacá, siglos XIX-XX}

El inicio del periodo republicano en el área que comprende el actual sur de Perú, altiplano boliviano y el norte de Chile, comenzó en 1810 y perduró hasta 1825. Este cambio de orden social significó un esfuerzo de modernización que intentó superar las contradicciones del mundo colonial. Los modelos institucionales importados de Europa no lograron borrar la trama social construida por más de tres siglos; así, casi todas las costumbres coloniales prolongaron su uso y se adaptaron paulatinamente a la incorporación de una ideología de corte ilustrado, donde se substituyeron los símbolos religiosos por símbolos nacionales. Las naciones se configuraron como una comunidad imaginada (Anderson 1993), en la que los nuevos símbolos cumplían una función aglutinante $y$, en la medida que transcurría el siglo XIX, se conformaron nuevas identidades. En los antiguos centros virreinales del sur de Perú y de la provincia de Charcas, actual Bolivia, se impuso el estilo neoclásico de derivación francesa en la arquitectura y la plástica, y una estética que hacía alusión a las glorias de Napoleón y a la democracia griega (Rossels 1996:44). Desde los centros administrativos, el nuevo pensamiento se irradió hacia las zonas periféricas que aún mantenían costumbres coloniales, lo que produjo importantes cambios hasta en los poblados más alejados.

Desde el punto de vista sonoro, el ejemplo más significativo de estos cambios lo constituyeron, en las celebraciones públicas, los himnos y las marchas; mientras que, en las tertulias, las danzas europeas fueron el elemento expresivo que exaltaba los nuevos valores burgueses. En este contexto, los bailes, las tonadas y tonadillas hispanas en auge en el siglo XVIII dejaron el protagonismo a los bailes señoriales centroeuropeos de coreografía compleja y en forma de contradanzas. Los salones de ciudades como Lima, Arequipa, Santiago, Sucre y La Paz adoptaron rápidamente los géneros musicales y coreográficos llegados desde los salones franceses e ingleses: la mazurca, la polka, la cuadrilla y el vals. Por ejemplo, en 1816, en la ciudad de Arequipa, estos bailes convivían con las danzas criollas y, en 1833, el vals ya presentaba características regionales (Vega Salvatierra 2018:216-217).

Con el paso del tiempo, el espíritu nacionalista promovió el surgimiento de nuevos géneros musicales, descendientes de las danzas pícaras hispanas -fandango, jota y bolero- que se denominaron bailecitos, bailes criollos o bailes de tierra (Claro 1979:53; Loyola 1980:17; Martínez y Palmiero 2000:703 y 711; Vega 1956:153-158). Estas danzas fueron practicadas por todos los sectores sociales y, en sus respectivas variantes regionales, se convirtieron con el tiempo en símbolos nacionales, con una fuerte connotación identitaria (Soux 1997:29; Spencer 2007 y 2009; Tompkins 2011:44). Una de las variantes representativas de la región sur andina fue seguramente la zamacueca, que se practicó con especial entusiasmo en Perú y en Chile (Palmiero 2014:216-217, 384-385; Tompkins 2011:110). En la región de Tarapacá, a finales del siglo XIX, se bailaba la chilena, una derivación de la zamacueca ${ }^{5}$, pero los ejemplos más significativos de este tipo de danzas fueron el baile y tierra y el cachimbo (Daponte 2006; 2010:71-73; 2019:124- 126; Loyola 1980). Otro género estrechamente ligado al sentido identitario peruano fue el yaraví que, por sus connotaciones indígenas: "ilustra la tendencia criolla a volverse hacia contenidos locales para construir una identidad propia, distinta de la española y cercana a la indígena" (Vega Salvatierra 2019:132).

Con la definición territorial de los nuevos Estados, la región de Tarapacá quedó bajo administración peruana. Este territorio inauguró el período republicano en un difícil contexto económico: la escasez de agua y el final del período argentífero produjeron un decaimiento de la economía de los oasis que provocó, entre otras cosas, la disminución de la producción vitivinícola en Pica (Bermúdez 1986:102) ${ }^{6}$. Aquellas familias tarapaqueñas que se habían enriquecido con la explotación del mineral de Huantajaya se trasladaron a los centros más importantes, como Lima y Arequipa, pero continuaron manteniendo vínculos económicos y familiares en la zona ${ }^{7}$. Hacia mediados del siglo XIX, se desarrollaron las industrias del guano y del salitre que se convirtieron en el principal motor económico de la región. La pequeña burguesía emergente, constituida por familias mestizas de la zona que se habían quedado en el territorio, orientó su economía hacia las nacientes industrias, mientras que la población más desfavorecida dejaba las faenas agrícolas y se empleaba en los principales centros mineros, en los puertos y en la arriería (Núñez 2004:89-90) (Figura 1). 


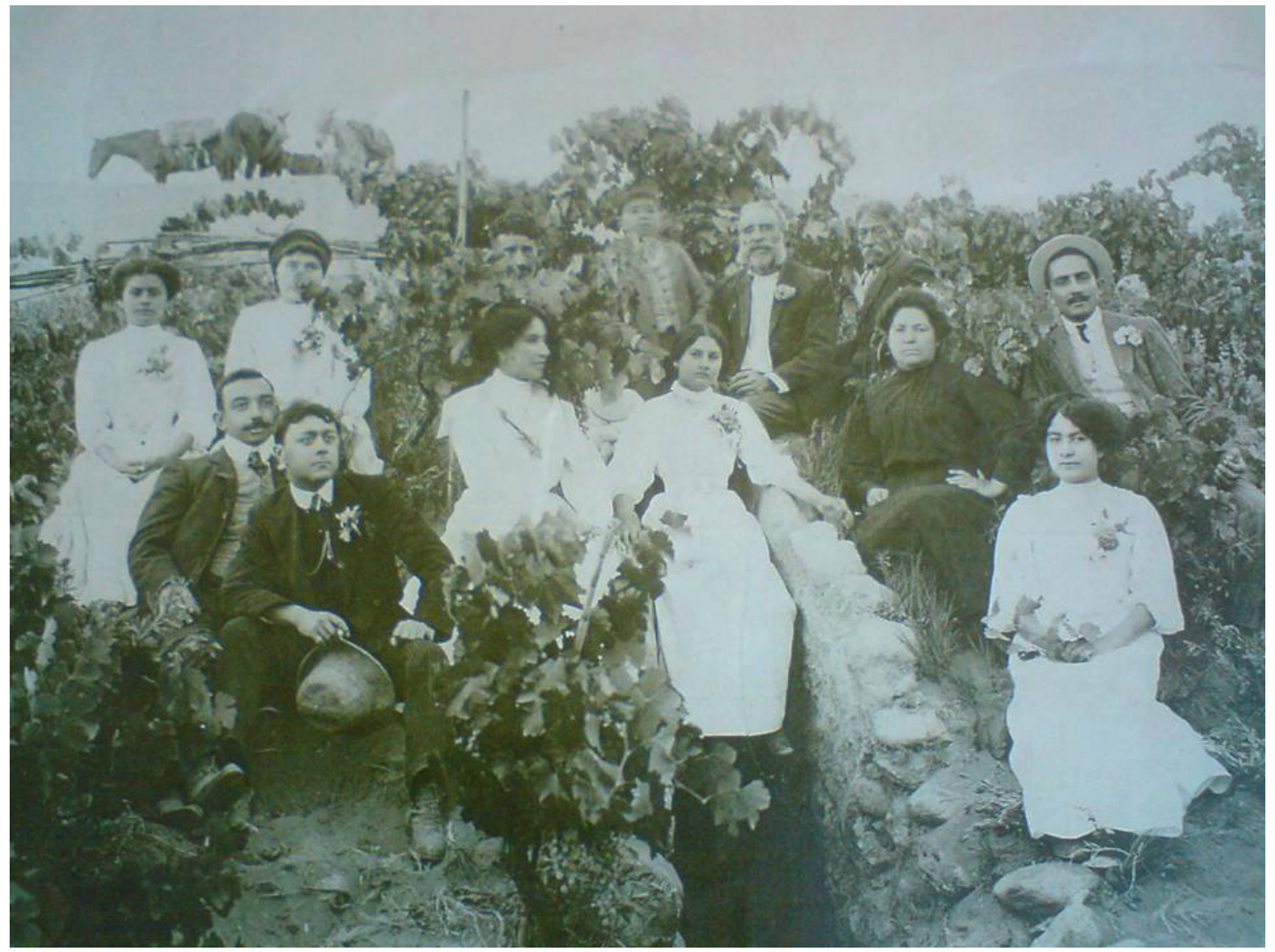

Figura 1. Convite en Matilla. Año 1900 c. Archivo familia Medina Paniagua.

En este contexto, las familias adineradas de Pica y Matilla se hicieron eco de las modas de las ciudades más importantes, influenciadas seguramente por la llegada de inversores limeños, chilenos y europeos, que atraídos por el salitre se habían afincado en la región. Con la adopción de las nuevas costumbres, llegaron las danzas europeas que, junto con los bailes criollos, amenizaron las tertulias saloneras ${ }^{8}$. De esta manera, hacia la mitad del siglo XIX, las reuniones festivas de la región no se diferenciaban mucho de las que tenían lugar en los salones de las ciudades importantes. Sin embargo, con el avanzar del siglo XIX, en las tertulias de ciudades como Lima y Arequipa se comenzó primero a interpretar música docta y se adoptó el formato de concierto privado con artistas invitados, para pasar posteriormente a reuniones poético-literarias con intervenciones de música "a libreto"; mientras que las danzas criollas y las tonadas populares amenizaban las reuniones de los sectores medio y bajo de la población (Martínez y Palmiero 2000; Merino 1990; Spencer 2007; Vega Salvatierra 2006:80). Por el contrario, los salones de Pica y Matilla mantuvieron vivas las tertulias de antaño, en la que los bailes de la tierra y los cantos tradicionales convivían con la cuadrilla, la polka y el vals y los intérpretes eran músicos aficionados, en su mayoría mujeres ${ }^{9}$.

Después de 1883, con la administración chilena, la economía de los oasis fue decayendo paulatinamente y varias familias piqueñas y matillanas, que eran dueñas de acciones en la salitrera, perdieron poder y propiedades y tuvieron que reinventar sus economías; de este modo, en los oasis se incrementó el cultivo de cítricos, mangos y guayabos. En este contexto, el Estado chileno realizó ciertas acciones para incorporar económica, jurídica y socialmente sus nuevos territorios. Comenzó entonces un proceso "chilenizador" que tuvo dos etapas: la primera, entre 1880 y 1907, se caracterizó por la introducción de símbolos nacionales patrios, en su mayoría ligados al imaginario militar; durante la segunda etapa, entre 1908 y 1929, los gobiernos aumentaron la presión hacia la población local, haciendo uso de un cierto grado de violencia (González 1994). El principal 
objetivo era erradicar del territorio todo lo que no fuese considerado chileno y varias familias de la zona fueron expulsadas del país ${ }^{10}$.

En los años sucesivos a la chilenización, entre 1930 y 1960, las autoridades mantuvieron la política de inserción de la región al Estado chileno; sin embargo, este proceso no tuvo la misma eficacia en el ámbito cultural. Es cierto que hubo excepciones, como fueron las teatralidades patrióticas en los actos cívicos y la inserción de himnos y marchas en las celebraciones religiosas, especialmente en la fiestas marianas y patronales, pero en las tertulias privadas, como los convites, el cambio fue más lento y tardío ${ }^{11}$. El objetivo principal de la censura fueron los textos de los cantos que se habían creado con ocasión de la guerra y postguerra, o que recordaban con añoranza al pasado peruano, como los nostálgicos yaravíes que mantenían vivo el vínculo cultural de estos oasis con la ciudad de Arequipa. Muchas familias conservaron tarjetas, cartas y documentos referentes al período peruano; continuaron utilizando sus símbolos, u otras expresiones culturales consideradas como tal, como herramientas de resistencia a la chilenización ${ }^{12}$ (Figura 2).

A pesar de los cambios políticos y administrativos, los convites en los oasis continuaron con el mismo formato hasta las décadas de1920-1930, momento en que hacen su aparición en la región la radio y el tocadiscos que difundieron nuevos géneros musicales: corridos mexicanos, boleros, valses populares limeños, pasodoble, foxtrot y tangos. En un primer momento, la música envasada compartió el espacio de las tertulias con los repertorios más tradicionales, y los músicos incorporaron nuevas formas y estilos de interpretación (Lloréns 1983:45). Pero el cambio generacional y la llegada de los "bailes modernos", hacia 1960, como el rock and roll y sus derivados, desplazaron a los cantores de cuecas, valses y yaravíes y las tertulias perdieron su formato tradicional. Paralelamente, el llamado folclorismo chileno, que impulsó la proyección escénica, y el neofolclor, difundido por la industria discográfica nacional -cuyo centro de difusión fue la ciudad de Santiago-, crearon un estereotipo de la música y danza "nortina" que fuera más acorde a los gustos del público masivo. Este hecho tuvo como consecuencia la introducción en la región de nuevos estilos para los mismos géneros: la "cueca nortina", el cachimbo cantado y con estructura de canción y el huayno que se denominó "trote" o "pasacalle nortino"; estas nuevas músicas, cuyos

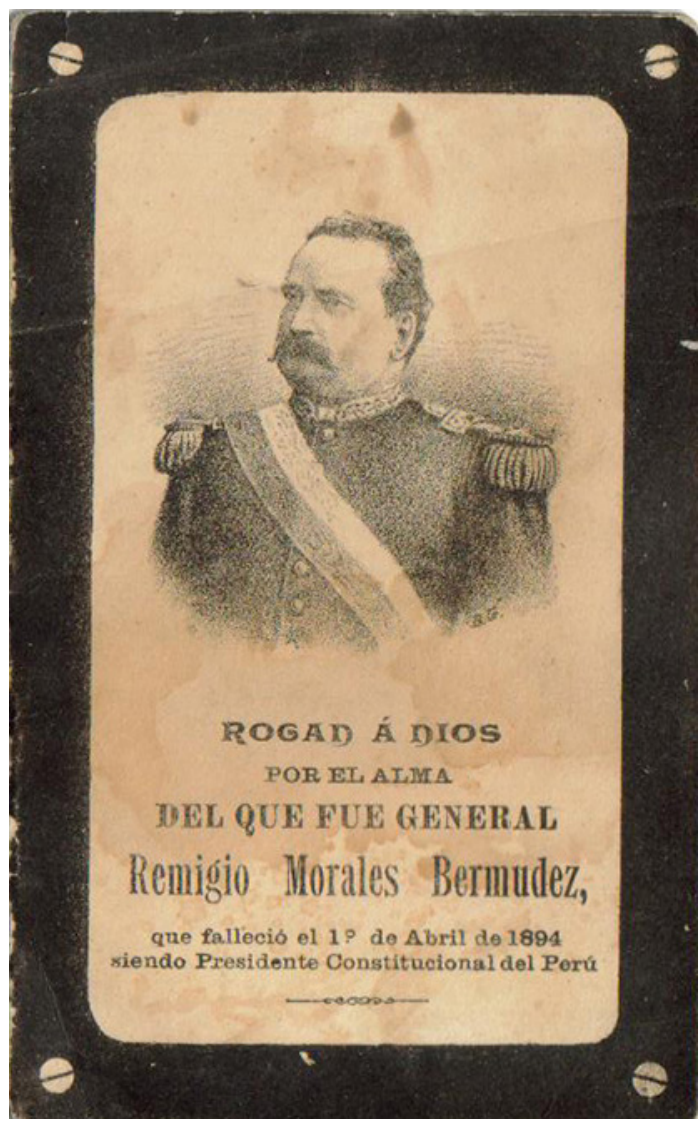

Figura 2. Tarjeta conmemorativa del presidente Morales Bermúdez. Archivo Lourdes Zúñiga Mitchel.

autores eran capitalinos, substituyeron paulatinamente el repertorio tradicional en los convites.

Finalmente, la instauración del toque de queda durante la dictadura militar de Augusto Pinochet, 1973-1989, que limitaba la vida nocturna y las reuniones sociales, determinó el fin de los convites como forma de sociabilidad y de reproducción musical privada; la difusión de la música quedó a cargo de las manifestaciones públicas, como las fiestas religiosas y civiles, además de la radio y la televisión ${ }^{13}$.

A pesar de los procesos culturales de las últimas décadas del siglo XX, las expresiones regionales pervivieron en algunas celebraciones públicas. Por ejemplo, en las fiestas populares religiosas y en el carnaval aún se escuchan y bailan, al son de las más modernas bandas de bronce, los huaynos locales, los valses peruanos, los cachimbos y las melodías propias de las cofradías religiosas, en especial aquellas inspiradas en las mascaradas bolivianas. Asimismo, la desaparición de la práctica del convite, con su 
antiguo aire señorial decimonónico y su desborde nocturno y callejero, cedió el puesto a celebraciones privadas de formato más moderno, con música envasada y bailes populares.

\section{Estructura de los convites, repertorio e instrumentos musicales}

Los convites que se celebraban en los oasis de Pica y Matilla se caracterizaron por el uso de espacios diversos. Estas tertulias, así como nos la han evocado sus últimos protagonistas, se desarrollaban en cuatro momentos: la chacra durante el día; el callejón al atardecer; el salón por la noche y las calles del pueblo al amanecer. En cada momento la música y el baile estaban presentes y, si bien los instrumentos musicales utilizados y buena parte de la música interpretada no tuvieran particular relación con lo que hoy conocemos como andino, la presencia de un constante continuиm sonoro pone en relación los convites con la tradición musical y cultural de estas poblaciones, para estas la presencia del sonido es imprescindible en el desarrollo de toda manifestación cultural y celebrativa. No es casualidad que uno de los relatos más difundidos en el norte chileno sea aquel del sireno, figura mítica y ligada al agua -elemento importante en una región desértica- que otorga el virtuosismo y sugiere melodías a los músicos para sus actuaciones (Álvarez 1997).

La importancia de la música en los convites se hace más evidente en el hecho que, por cada uno de los momentos espaciotemporales en que se articulaba la tertulia, era necesario recurrir al uso de danzas y cantos apropiados: "El peral se canta generalmente cuando se regresa de un paseo, convite como se le llamaba antes, a las chacras y, desde luego, una vez que oscurece, uno viene a cualquier casa donde haya un piano a seguir la fiesta, y por los callejones se venía cantando el peral" (Luza 1967).

La particular organización espaciotemporal de los convites se debió seguramente a la relación que existía, y existe todavía, entre las viviendas y las zonas de cultivo. En estos oasis, la presencia y el manejo de las aguas subterráneas determinaron la estructura y el crecimiento del pueblo; la existencia de socavones y el sistema de riego por inundación de los predios cultivables obligó a los habitantes a construir sus viviendas en la parte alta para evitar el contacto directo con las aguas canalizadas (Daponte 2004:104-105) ${ }^{14}$. Sin embargo, la relativa cercanía de los campos a las viviendas facilitó el desarrollo de los convites y la creación, en las chacras, del "solaz" 15 , un espacio que utilizaba aquellos elementos que definían el patio de la vivienda: la pérgola, los asientos y las flores decorativas. Su objetivo principal fue propiciar el descanso y la convivencia (Daponte 2004:78) (Figura 3) y, de este modo, las familias tarapaqueñas empezaron a considerar sus tierras no solo como lugares de cultivo, sino también como espacios de diversión y ostentación de poder y riqueza; algo de lo que estar orgullosos.

Esta forma de sociabilidad nos recuerda la costumbre burguesa, muy decimonónica, de realizar paseos al campo. Es interesante notar la similitud entre la estructura de los convites de los oasis con el testimonio de Félix Reyes Ortiz que, en 1860, observaba cómo las familias paceñas se entretenían organizando fiestas bailables en el campo de los alrededores: "Otra costumbre muy criolla era la de los optapis, paseos en grupo a los alrededores de la ciudad (Potopoto y Obrajes) a los cuales los hombres llevaban los licores y las damas la comida. [...] Después la fiesta terminaba en casa de uno de los asistentes" (Soux 1997:234) ${ }^{16}$.

En cuanto a la música que se consumía en el espacio de la chacra, ese era el lugar en que los instrumentos de cuerdas frotadas y pulsadas tomaban mayor protagonismo y la "cueca peruana", como la llamó Nelly Cayo (comunicación personal 1994), era la reina indiscutida de la fiesta. Refiriéndose a los convites que se celebraban en ocasión de la vendimia, algunos testimonios comentaban que: "bailaban cueca los veteranos, valses a veces, pero todo era gente mayor, entonces a las cuecas le daban y a los jarros con vino" (Elsa Oxa comunicación personal 1997); "Los destapes se celebraban con cueca, las cuecas peruanas que se cantaban acá, cuecas muy bonitas, las letras sobre todo" (Nelly Cayo comunicación personal 1998). Los cantores más famosos eran recordados con admiración: "Las cuecas se cantaban con guitarras, Manuel Arroyo, ¡Ese cantaba lindo!, José Ceballos tenía muy buena voz" (Elsa Oxa comunicación personal 1997) (Figura 4).

Otros géneros que también destacaron en este espacio fueron los bailes de tierra cantados ${ }^{17} \mathrm{y}$ el yaraví, que en esta zona presenta particularidades que detallaremos más adelante.

Después de un día bajo los árboles, la salida de la primera estrella era el anuncio de que la 


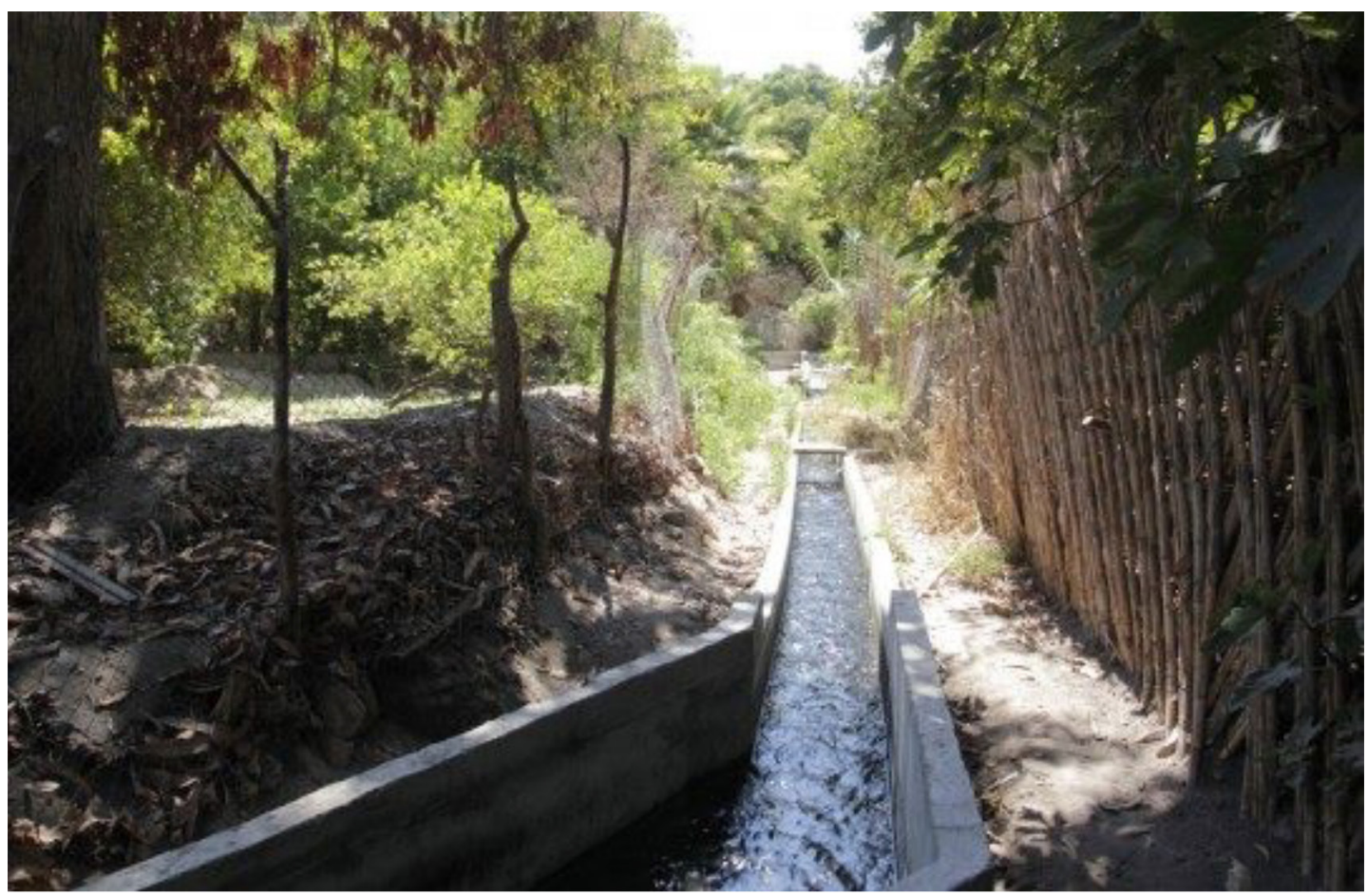

Figura 3. Canal de una chacra del sector de Enrique. Foto Gino Daponte.

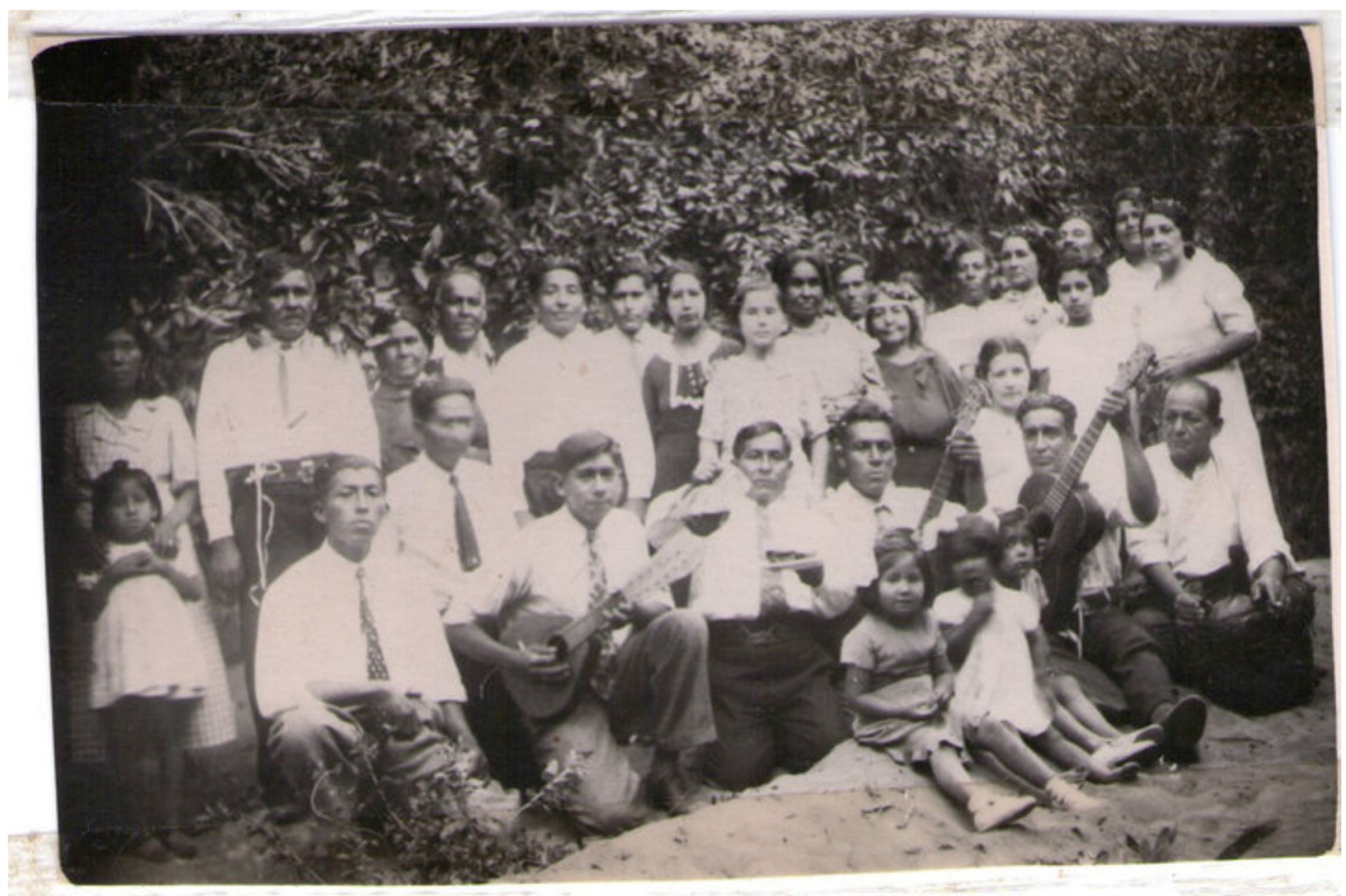

Figura 4. Convite en Pica. Familias Huarcaya, Montano y Vilaxa. Año 1950 c. Archivo de Jaime Castro Vilaxa. 
celebración terminaba en la chacra y se debía continuar hacia el salón de la familia anfitriona. Los contertulios se encaminaban por los caminos de tierra cantando un pasacalle y acompañándose con guitarras ${ }^{18}$. Históricamente, la comunicación entre las viviendas y las chacras se hizo posible con la creación de callejones, caminos que constituyen todavía hoy el entramado que conecta el pueblo con los cultivos (Daponte 2004:106). El paseo por las tibias arenas y a la sombra de los árboles que delimitan los predios se ha convertido en un lugar mítico de la fascinación del oasis y son considerados hoy un recorrido turístico.

Una vez llegada al pueblo, la comitiva era recibida en los frescos salones preparados para la ocasión: en la sala principal, situada siempre entrando a la izquierda, se posicionaban las sillas a lo largo del perímetro y se dejaba despejado el centro de la habitación para los bailarines. A un costado, se encontraba el piano que, tocado principalmente por las señoras, sustituía a las guitarras en la interpretación de las danzas propias del salón decimonónico ${ }^{19}$. El período que nos interesa, y en que posiblemente se instituyó el tipo de convite al que nos referimos, coincide con la creación de una vivienda que fue la expresión de la burguesía ligada al auge salitrero. Se trata de un tipo de casa que sobrevivió a los cambios modernos y que embellece hoy las principales calles de los pueblos: "Durante este periodo se abandona el canon colonial y se construye en el orden de pasadizo central y habitaciones laterales, conservándose el balcón de fachada. [...] Este tipo de vivienda no se ha renovado y son las mismas del periodo salitrero" (Daponte 2004:152) (Figura 5).

Normalmente, el baile en el salón empezaba con la cuadrilla; Enrique Luza especificaba que se trataba de la "Cuadrilla de Lanceros", seguida de mazurcas, polkas y contradanzas, para terminar con los bailes criollos como la cueca y el cachimbo ${ }^{20}$.

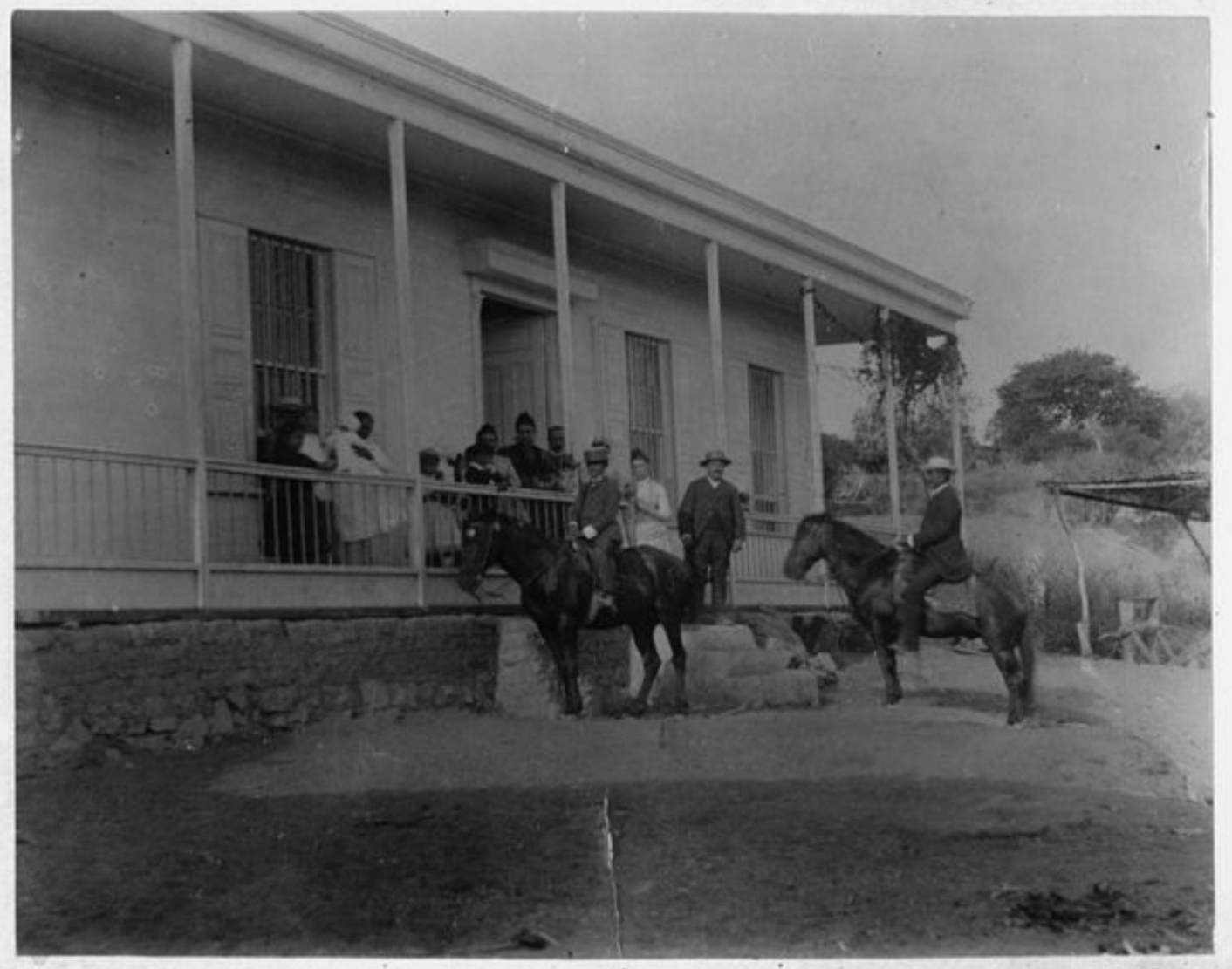

Figura 5. Familia piqueña posando frente a su casa en el sector Resbaladero. Año 1900 c. Archivo Museo Municipal de Pica. 
Esta misma organización musical la encontramos también en la descripción de una fiesta ocurrida en 1853 en casa de una familia burguesa de La Paz; según el médico y botánico inglés Hugh Algernon Weddell: "Luego que la orquesta hubo entonado un aire de cuadrilla, las danzas se formaron y el baile comenzó"; más adelante Weddell informaba que, después de varios giros de danza y varias copas: "Una nueva fase del baile iba a comenzar. Las danzas nacionales o bailecitos fueron introducidos" (Soux 1997:235).

Naturalmente, este formato de noche bailable dejaba espacio también a la improvisación y a los gustos personales. Por ejemplo, el repertorio del músico Enrique Luza comprendía composiciones originales, además de arreglos de melodías tradicionales profanas y religiosas, como por ejemplo su "Fantasía navideña"21; es evidente que el resultado final eran unas veladas muy variadas en géneros musicales y estilos. Además, la presencia de algunas obras clásicas entre los libros de música que han llegado hasta nosotros demuestra que este género no era del todo desconocido a los músicos locales y es posible que, de manera esporádica, se interpretaran obras de compositores más conocidos o consagrados (Figura 6).

En cuanto a los instrumentos musicales usados en el salón, el piano era el más apreciado y, aunque a veces se tocaran en este las danzas criollas, como por ejemplo el cachimbo, estas adquirían un aire elegante y más cónsono a aquellos tablones alfombrados. En los salones era bastante común la combinación de instrumentos de cuerdas, como violines, bandurrias y mandolinas y al momento de los bailes criollos hacía siempre su aparición el bullicioso bombo. Este instrumento "daba el aire" y hacía la danza salerosa (Luza, comunicación personal 1994) y Regina Bejarano decía que: "el bombo le da esto al cachimbo", realizando a la vez un movimiento de cadera (Loyola 1994:41).

Las danzas decimonónicas importadas, como la mazurca, el vals, la polka y la cuadrilla llegaban al oasis en formato de partituras, los músicos del pueblo las interpretaban en sus instrumentos y, en el caso de las obras de mayor éxito, estas se aprendían de memoria y se convertían en patrimonio musical colectivo. Enrique Luza informaba que, cuando alguna de las pianistas bajaba al puerto de Iquique (se trataba principalmente de mujeres), realizaba una visita a la casa de música y volvía al pueblo con las últimas novedades editoriales. También contaba

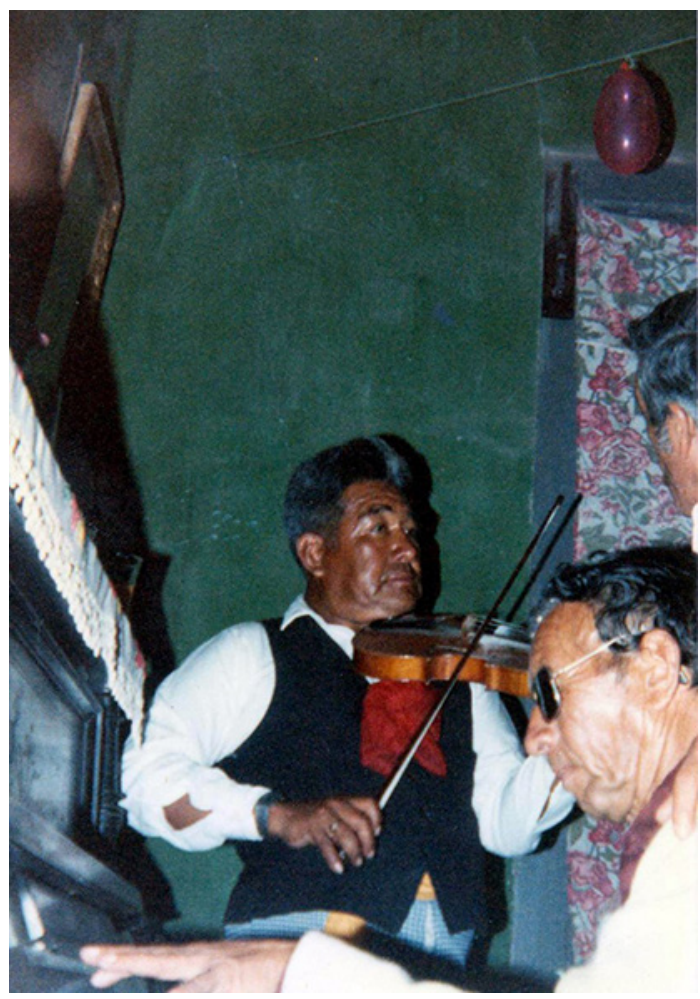

Figura 6. Enrique Luza, piano y Augusto Vilca, violín. Año 1980 c. Archivo Biblioteca de Pica.

que todas las pianistas leían música y que algunas, como Rogaciana Núñez, tenían una excelente lectura a primera vista.

Después de bailar y cantar toda la noche, a las primeras luces del alba se daba por terminada la fiesta. Los contertulios se retiraban a sus casas cantando otro pasacalle, la Cuculí, lo que provocaba a menudo las protestas de algunas autoridades, como fue el caso del subdelegado Ambrosio Valdés Carrera que, en 1884, denunciaba:

Desde el día en que su señoría dejó este pueblo, los señores Luza y amigos han estado en permanente orgía. Nada sería que tengan su tertulia, si la tuviesen con decencia, pero sucede que hasta las 11 de la noche sostienen su diversión solo con violines, pero pasada esa hora, llevan bombo y la borrachera más espantosa termina con gritos y cantos, recorriendo las calles de ese modo, sin que nadie pueda dormir pues la fiesta termina con la luz del día (Bermúdez 1986:72). 


\section{Características del repertorio regional}

Además de las danzas de clara procedencia europea, el repertorio musical de los convites estaba conformado por cuecas, cachimbos, baile y tierra, yaravíes y pasacalles. Si bien algunos géneros, como el yaraví, son comunes a otras áreas geográficas, adquieren características particulares en los oasis estudiados, de manera que podemos hablar de un repertorio regional. Contrariamente a las danzas europeas, este repertorio se aprendía por tradición oral, aunque no faltaron los arreglos en partitura, especialmente para piano, realizados por algún músico local.

\section{Los bailes criollos}

Acompañada principalmente por la guitarra, la cueca de la región era una danza en tonalidad menor, cuyas formas métricas eran la copla octosílaba y la seguidilla, entre estas se introducían versos sueltos de doble sentido. A diferencia de la actual cueca, la estructura no era fija y el número de seguidillas era variable y dependía del momento y de la "chispa" de cantores y bailarines. Usualmente, la danza se acompañaba con palmoteos y percusiones.

La cueca, como el cachimbo y el baile y tierra, pertenecía al conjunto de los bailes criollos decimonónicos que se caracterizaban por ser danzas de parejas independientes, por el uso del pañuelo y de pasos zapateados o resbalados. En cuanto a la estructura de estos bailes, hay ciertas diferencias entre la cueca y el cachimbo y el baile y tierra. Para el caso de la cueca, esta contaba de tres secciones: una introducción para el posicionamiento de los bailarines, una primera figura para la copla y algunas figuras para las seguidillas, en que el ímpetu de los bailarines aumentaba en intensidad; la cueca terminaba cuando el cantor interpretaba dos versos rimados entre sí, llamados remate. En el caso del cachimbo y del baile y tierra, la parte central bailable se llamaba "dulce, encuentro o desprecio"; mientras que la parte final, llamada "fuga o toreo", se realizaba bailando de manera más rápida y con movimientos del cuerpo más pronunciados (Daponte 2006:63). De la presencia de estos bailes en los oasis, la tradición oral argumenta que una danza llamada baile y tierra apareció en los salones de los "señores de las viñas" de Pica y Matilla, espacio que ocupó hasta las décadas de 1950-1960. El estilo elegante parece haber sido una de las características fundamentales del baile y tierra (Díaz y Daponte 2017) y Enrique Luza comentaba que era una danza elegante y salerosa (comunicación personal 1994).

La historia del baile y tierra se entrelaza a la del cachimbo, que al parecer fue una versión más popular del mismo baile; el baile y tierra fue probablemente imitado y adoptado por los trabajadores de las haciendas y practicado en otros espacios sociales, como la plaza o el "parabién del pueblo", durante las fiestas comunitarias. En este nuevo contexto, se mantuvo la estructura coreográfica y la forma musical del salón, pero la danza adquirió otro estilo y carácter interpretativo y, desde el siglo XX, recibió el nombre de cachimbo 22 (Daponte 2019:250). El baile y tierra desapareció probablemente en el mismo período y fue recordado y revivido a menudo por los más viejos habitantes de la región, aunque las melodías cantadas se habían casi perdido (Díaz y Daponte 2017) ${ }^{23}$ (Anexo 1).

Si bien el cachimbo y la cueca "peruana" se bailaron en algunos salones, fueron siempre consideradas como danzas populares, propias de los parabienes o plaza de los pueblos; situación que continúa hasta nuestros días. Actualmente, las melodías de los cachimbos son solo instrumentales y son tres: Cachimbo de Pica, Cachimbo de Mamiña y Cachimbo de Tarapacá, este último es el más conocido y difundido ${ }^{24}$. Las tres melodías vienen interpretadas hoy por las bandas de bronces, integradas por músicos aficionados (Daponte 2019:236).

En cuanto a la cueca, esta fue decayendo especialmente durante el período de la dictadura, momento en que se asistió a una nueva y más radical chilenización. Además, desde el movimiento del neofolklor, aparecieron las cuecas de autor, como la famosa cueca Caliche, de Calatambo Albarracín, que se convirtió en un referente para otros autores ${ }^{25}$. Hoy se escuchan solamente seis cuecas y en formato instrumental, tres interpretadas por las bandas de bronces y otras tres difundidas por las tropas de lakas. Estas cuecas aparecieron a mediados del siglo XX y no están relacionadas ni con la cueca tradicional ni con aquellas de autor.

\section{El yaraví}

El yaraví es un género preminentemente literario que se expresa en melodías cantables con acompañamiento de algunos instrumentos como la guitarra, el violín o el piano. Ya en el siglo XVIII se reconocía al yaraví como un género musical 
Cachimbo de Tarapacá

versión Enrique Luza, Pica 1967

trascriptor Tiziana Palmiero
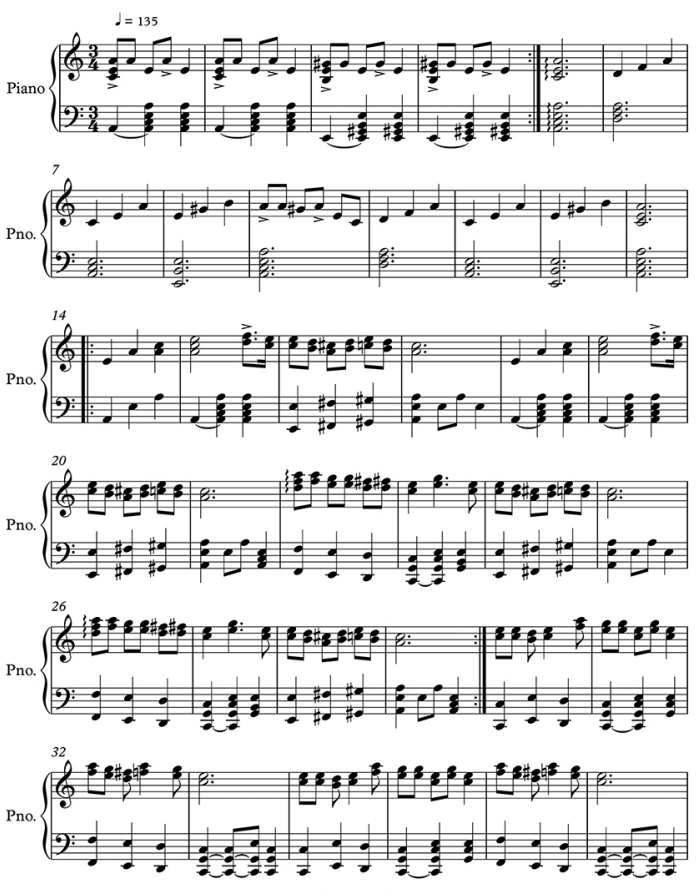
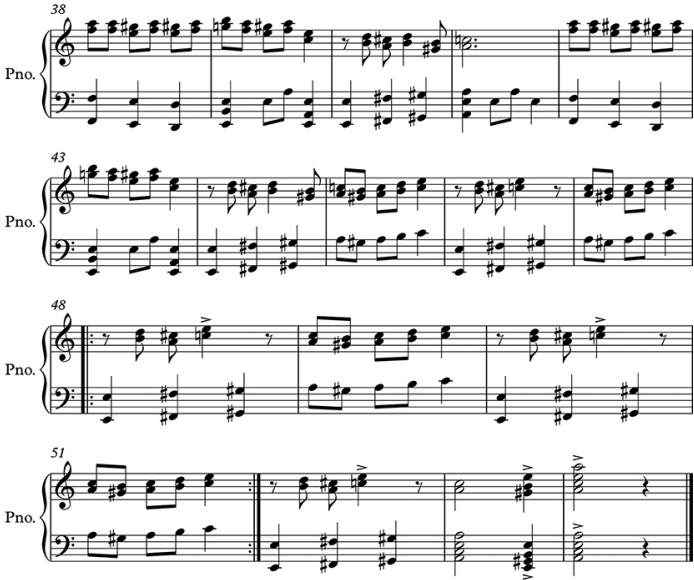

Anexo 1. Partitura del Cachimbo de Tarapacá, versión Enrique Luza, 1967.

peruano (Vega Salvatierra 2019). Famosos fueron los yaravíes del escritor independentista Mariano Melgar, que escribía a comienzos del siglo XIX y, en la misma época, en los teatros de Lima encontramos al yaraví compartiendo escenario con las tonadillas locales, como nos informaba el diario El Telégrafo de Lima el 16 de octubre de 1827: "Aficionados a la música y al canto de mi país, y deseosos los que concurren frecuentemente al Teatro de oir la tonadilla de los indios, y yaravies peruanos" (Estenssoro 1989:57). Finalmente, este género poético musical, desde las elites locales, se difundió y popularizó manteniendo un creciente éxito en Perú hasta nuestros días. Seguramente bajo la influencia musical arequipeña, Tarapacá cultivó este melancólico género, llegó a producir melodías y textos originales en que, además de los temas de amor, se comentaban las desgracias sufridas por la región a consecuencia de la Guerra del Pacífico y de la ocupación chilena, como se puede apreciar en esta copla que recordaba Roberto Gómez en 1994: "O provincia desgraciada / manantial de tus riquezas / hoy te ves sumergida / por la nación más perversa" (comunicación personal).
Los yaravíes en Tarapacá eran principalmente de dos tipos: en aquellos llamados ruedas, los cantores se turnaban e improvisaban las coplas, que podían ser libres o a temas; otros eran los yaravíes con un título y una historia conocida, en este caso todos cantaban juntos. Cantado, y a veces tocado en violín, el yaraví tarapaqueño tenía un acompañamiento simple en que la guitarra realizaba el mismo rasgueado de la cueca, pero más lento y marcando el compás ${ }^{26}$. Este género sufrió un notorio declive durante la chilenización, ya que evocaba el pasado peruano, y no fue asimilado a la música chilena nortina. Los últimos versos se dejaron de interpretar hacia 2013 con la muerte de Roberto Gómez.

\section{Los pasacalles o huaras}

El término huara es atribuible ya sea al idioma quechua como aimara: en quechua quiere decir "lucero de la mañana" y en aimara, huarahuara significa "estrella" (Santo Thomas 2006:627[1560]; Bertonio 1984:149[1612]). Un nombre que hace referencia a una estrella es muy apropiado para estos cantos, ya que la huara Peral, o Palalita, se 
cantaba al final del día con la aparición de la primera estrella, cuando los contertulios se encaminaban por los callejones que los llevaban al salón (Luza 1994); mientras que la huara Cuculí se cantaba por las calles del pueblo al amanecer, cuando en el cielo la última estrella anunciaba el fin del convite y el momento de volver a los hogares. Las coplas de las huaras no eran fijas, podían ser improvisadas o simplemente ser estrofas prestadas de algunos otros cantos, como los yaravíes o las cuecas; dependiendo del carácter de la ocasión festiva, las coplas eran románticas, melancólicas, o contenían argumentos alusivos de doble sentido.

Estos simples cantos responsoriales en tono menor eran guiados por un guitarrista encargado de improvisar las coplas, a las que respondía la comitiva alternando dos versos: en el caso del Peral el coro contestaba "peral, peral" y "por la libertá"; en la Palalita de Matilla, que tiene la misma melodía del Peral, se contestaba "palalita" y "corazoncito".

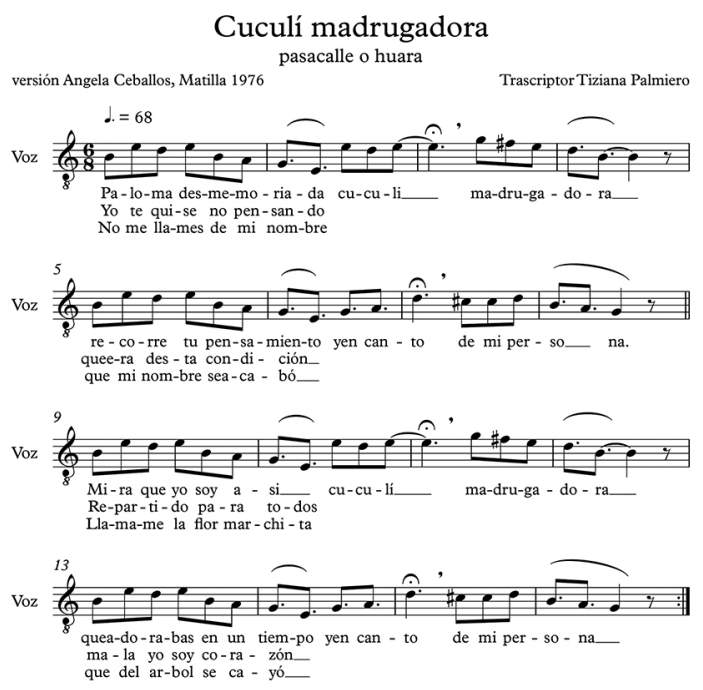

Copyright musicasireno

Anexo 2. Partitura del Cuculí madrugadora, versión Ángela Ceballos, 1976. Recopilador María Ester Grebe.
En cuanto a la Cuculí, los versos del coro eran en ambos pueblos "cuculí madrugadora" y "en canto de mi persona" (Anexo 2).

Las huaras son quizás el género más original de la región de Tarapacá, ya que no se conocen en otros territorios. Si bien han existido arreglos para piano y hoy se canten en algunas reuniones familiares, estas melodías son ligadas al momento específico del desplazamiento y se presentan como un elemento articulador del espacio y el tiempo; ya que indican la transición entre las diferentes partes del convite. Además, el canto grupal de las comitivas que se reversaban en los callejones y las calles del pueblo, al atardecer y al amanecer, comunicaba la alegría de la fiesta y transformaba los pasacalles en una declaración de presencia y pertenencia de las familias al territorio.

\section{Conclusiones}

Podemos concluir afirmando que los convites fueron un importante espacio de sociabilidad y de transmisión de conocimientos musicales entre la población de los oasis de Pica y Matilla; la presencia de música de diferentes orígenes y géneros hizo de estas fiestas un lugar de encuentro entre los productos culturales de las diferentes clases sociales. El período de desarrollo de estas tertulias corresponde al auge de la industria salitrera, 1850-1970, hecho que provocó grandes cambios sociales y económicos en la región. A causa de la particularidad urbanística y social de los oasis, la estructura de estas fiestas se presenta como una síntesis de los paseos al campo, típicos de la burguesía decimonónica, con las noches bailables de los salones citadinos. Además, la particular génesis de estos pueblos y su atormentada historia se reflejaron en las danzas y cantos de estas fiestas en que confluyeron elementos coloniales y republicanos. Estas prácticas sobrevivieron al impacto de la chilenización de comienzos del siglo XX, mas no a la política cultural y social de la dictadura de Pinochet, que, con la aplicación del toque de queda, puso fin a estas tertulias. El más reciente fenómeno de la globalización trajo consigo el despertar de identidades locales que encuentran su expresión hoy en la creación de asociaciones y clubes cuyo fin es el rescate de la cultura regional. Especialmente a ellos va dedicado este trabajo. 


\section{Referencias Citadas}

Álvarez, L.

1997 "Relatos y tradiciones orales andinas. Sireno: Dios de la música". Diálogo Andino 16:49-59.

Anderson, B. 1993 Comunidades Imaginadas. Fondo de cultura económica, México.

Bermúdez, O. 1986 El oasis de Pica y sus nexos Regionales. Ediciones Universidad de Tarapacá, Santiago.

Bertonio, L.

1984 [1612] Vocabulario de la Lengua Aymara. Centro de Estudios de la Realidad Económica y Social, Cochabamba.

Claro, S. 1997 Oyendo a Chile. Andrés Bello, Santiago.

Daponte, J.F.

2006 La pervivencia de la cachua y el baile y tierra en el oasis de Pica. Identidad de una sociedad barroca americana. Actas del VI Encuentro Simposio Internacional de Musicología: La Danza en la Época Colonial Americana. Editor Aurelio Tello, pp. 49-70. Asociación Pro Arte y Cultura, Santa Cruz de la Sierra.

2010 El aporte de los negros a la identidad musical de Pica, Matilla y Tarapacá. Consejo Nacional de la Cultura y Las Artes, Santiago.

2019 Aunque no suena tan negro, es música de negros. Presencia y aporte de los esclavos africanos y a la música tradicional del Norte Grande de Chile. Tesis para optar al grado de Doctor en Musicología. Universidad de Valladolid, España.

Daponte, G.

2004 El agua constructora del orden espacial, urbano y arquitectónico en San Andrés de Pica. Tesis para optar al título de arquitecto. Escuela de Arquitectura, Universidad Arturo Prat, Iquique.

Díaz, A.

2011 "En la pampa los diablos andan sueltos: Demonios danzantes de la fiesta del santuario de La Tirana". Revista Musical Chilena 65(216): 58-97.

Díaz, A. y Daponte, J.F.

2017 Investigación sobre la danza del Cachimbo en tres comunas focalizadas de la Región de Tarapacá; Pica, Huara (Tarapacá) y Mamiña. Expediente Cachimbo. Servicio del Patrimonio del ministerio de las Culturas Las artes y el Patrimonio y Universidad de Tarapacá. Valparaíso.

Díaz, A. y Lanas, P.

2015 "Danza y devoción en el desierto: Obreros e indígenas en la fiesta de la Virgen del Carmen de La Tirana, Norte de Chile (siglo XX)". Latin American Music Review 36/2:145-169.

Díaz, A.; Mondaca, C. y Ruz, R.

2000 "Música y músicos aymaras del norte chileno". Dialogo Andino 19:61-84.

Focacci, G. y Pizarro, E.

2000 "Relatos de cronistas sobre instrumentos musicales andinos. Presencia de ellos en la arqueología de Arica". Dialogo Andino 19:33-50.

Henríquez, P. 1996. ¿Por qué bailando? Estudio de los bailes religiosos del Norte Grande de Chile. Printext, Santiago.

Estenssoro, J.C.

1989 Música y Sociedad Coloniales1680-1830. Colmillo Blanco, Lima.
Lloréns Amico, A.

1983 Música popular en Lima: criollos y andinos. Instituto de Estudios Peruanos, Lima.

Loyola, M.

1994 El Cachimbo Danza Tarapaqueña de Pueblos y Quebradas. Ediciones universitarias de Valparaíso, Valparaíso.

Luza, E.

1967 Saludo Musical Piqueño. Grabación inédita en posesión de Rosa Arenas.

Luza, E.

1996 "Apuntes de los antiguos carnavales piqueños". Recopilación de música, poesía y prosa. Recopilador Amelia Zañartu de Luza. Manuscrito en posesión de la Biblioteca de Pica s/p.

Martínez, J. y Palmiero, T.

2000 El salón decimonónico como núcleo generador de la música chilena de arte. Actas del Primer Congreso Iberoamericano de Musicología: La Música en los Salones del siglo XIX, Coordinador José Peñín, pp. 697-754. Fundación Vicente Emilio Sojo y Universidad Central de Caracas, Caracas.

Merino, L.

1990 "Repercusiones nacionales e internacionales de la visita a Chile de José White". Revista Musical Chilena 44-173:65-113.

Núñez, L.

2004 La Tirana del Tamarugal. Ediciones Universitarias, Universidad Católica del Norte, Antofagasta.

Palmiero, Tiziana.

2014 Las láminas musicales del códice Martínez Compañón, Trujillo del Perú, 1782-85: espacio de mediación entre las ideas ilustradas de un obispo y las teorías y prácticas musicales de los habitantes de su diócesis. Tesis para optar al grado de Doctor en Estudios Latinoamericanos. Universidad de Chile, Santiago.

Rossells, B.

1996 Caymari vida: La Emergencia de la Música Popular en Charcas. Editorial Judicial, Sucre.

Santo Thomas de, D.

2006 [1560] Léxico Quechua, editor J. Szemiñski. Convento de Santo Domingo, Sociedad Polaca de Estudios Latinoamericanos, Universidad Hebrea de Jerusalem, Ediciones El Santo Oficio-Códice Ediciones S.A.C., Lima.

Soux, M.E.

1997 "Música de tradición oral en la Paz: 1845-1885”. Música en la Colonia y en la República, editores C. Seoane U. y A. Eichmann, pp. 219-248. INDEAA Ediciones, La Paz.

Spencer, C.

2007 "Imaginario nacional y cambio cultural: circulación, recepción y pervivencia de la Zamacueca en Chile durante el siglo XIX". Cuadernos de Música Iberoamericana 14:143-176.

2009 "Apología del mestizaje, exaltación de la nacionalidad. El papel del canon discursivo en la discusión sobre autenticidad y etnicidad de la (zama) cueca chilena". Trans. Revista Transcultural de Música, sin mes, 1-12. http://www.redalyc. org/articulo.oa? $i d=82220946015$ (14 mayo 2016).

Tompkins, W.

2011 Las Tradiciones Musicales de los Negros de la costa del Perú. Centro de Música y Danza de la Pontificia Universidad Católica de Perú, Lima. 
Uribe Echeverría, J.

1973 Fiesta de la Tirana de Tarapacá. Ediciones Universitarias de Valparaíso, Chile.

Van Kessel, J.

1989 La Iglesia Católica entre los Aymaras. Ediciones Rehue, Santiago.

Vega, C.

1956 El origen de las danzas folklóricas. Ricordi Americana, Buenos Aires.

Vega Salvatierra, Z.

2006 Vida musical cotidiana en Arequipa durante el oncenio de Leguía (1919-1930). Asamblea Nacional de Rectores, Lima.
Vega Salvatierra, Z

2018 "La partitura como testimonio de la tradición. Un caso sobre identidad y etnomusicología en la historia". Cuadernos de música iberoamericana, 31:211-233.

Vega Salvatierra, Z.

2019 De la tristeza a la identidad: El yaraví peruano en las fuentes escritas de los siglos XVIII, XIX y XX. Tesis que para optar por el grado de Doctor en Música (musicología). UNAM, México.

Wormand, A.

1968 Frontera Norte. Editorial del Pacífico S.A., Santiago.

Notas

1 Los Bermúdez era una antigua familia de viñateros acaudalados; uno de sus componentes fue presidente de Perú: Remigio Morales Bermúdez (Pica, 30 de septiembre de 1836 - Lima, 1 de abril de 1894).

2 La fiesta de La Tirana es una de las celebraciones de culto religioso mariano más grandes de Latinoamérica que sin duda sigue despertando el interés de muchos investigadores.

3 Se han realizado grabaciones y entrevistas al músico Enrique Luza tocando el piano en 1967 y el órgano en 1994; a Roberto Gómez en 1994, 1998 y 2004, tocando guitarra y cantando. Además, entre 1994 y 2015 se han realizado numerosas entrevistas: Elsa Oxa 1997; Sara Oxa 2002; Nelly Cayo 1998; Luz Morales 2002; Roberto Palape 1998; Renée Luza 1997; Grimanesa Ceballos 1997; Percy Loayza 1997.

$4 \quad$ Los clubes de cachimbo de Pica y Matilla son organizaciones comunitarias que mantiene viva la tradición de algunas danzas y cantos que fueron importantes en la región. Entre las diversas actividades se han preocupado, guiados por los más ancianos, de recrear, en sus propias tertulias, los convites de antaño. Los autores han sido invitados a algunas de estas reuniones en las que han tenido la ocasión de tocar sus instrumentos y de conversar y compartir las experiencias y recuerdos de los concurrentes.

5 "En La Tirana [poblado ubicado en la provincia del Tamarugal, en la actual región de Tarapacá] solo encontré a un señor Contreras; único beneficiador existente de metales; los jóvenes actuales de esa población tienen a menos aprender el oficio; prefieren ocuparse de tocar la guitarra o bailar la chilena" (Basadre 1884: 184).

6 Durante la Colonia, en Pica y Matilla se había desarrollado una importante industria vitivinícola.

7 Huantajaya fue una importante mina de plata, reactivada a finales del siglo XVIII.

$8 \quad$ Según Enrique Luza (comunicación personal 1994), músico piqueño, las danzas europeas llegaron alrededor de 1850 y se bailaron en Pica hasta 1960, aproximadamente.

9 No fue así en las oficinas salitreras, cuyos dueños eran europeos y aristócratas chilenos, en que el formato de salón literario con música docta floreció y fue replicado por las filarmónicas obreras.

10 Las familias más favorecidas de la región, que mantenían vínculos políticos importantes con Perú, fueron consideradas peligrosas por la nueva administración. Además, algunos pobladores, que no quisieron nacionalizarse, fueron perseguidos por las ligas patrióticas y forzados al exilio.

11 Una de las principales actividades chilenizadoras que realizaron los nuevos obispados fue la nacionalización de la fiesta religiosa. La atención de las autoridades se centró especialmente en el Santuario de la Virgen de La Tirana, que en aquella época se erigía como el principal centro de peregrinación de la pampa salitrera, convirtiendo la Virgen del Carmen (patrona de Chile) en: "La Virgen del Carmen de La Tirana, Patrona de Chile y Generalísima del Ejército de Chile" (Núñez 2004:92). Los otros santuarios de importancia del periodo colonial y peruano fueron desatendidos y, los que estaban en las zonas de conflicto fronterizo, censurados, como el de la Virgen de las Peñas en Arica (Van Kessel 1989:24).

12 En estos oasis, durante las fiestas religiosas, algunas familias que tenían la ocasión de ejercer el alferazgo de la fiesta patronal colocaban, junto al santo, las dos banderas, peruana y chilena; en cuanto a las danzas, el cachimbo, considerado como un resabio de la peruanidad, se practicó durante la primera mitad del siglo XX como una forma de resistencia y de afirmación de la identidad tarapaqueña; lo que permitió que sus melodías y coreografías llegaran hasta nuestros días (Díaz y Daponte 2017).

13 La región, por ser fronteriza, fue objeto de una exacerbada política nacionalista: se instauró en las escuelas el teatro histórico, cuyo argumento era principalmente la Guerra del Pacífico; se fomentaron los desfiles semanales de militares y escolares; se impuso el uso de banderas e himnos chilenos en todas las manifestaciones públicas. Al mismo tiempo, la televisión contribuía a imponer la imagen de un Chile homogéneo inspirado en la cultura de la región central del país y se difundieron los campeonatos escolares de cueca y los conjuntos folclóricos escolares dedicados a interpretar este baile que fue declarado baile nacional por un decreto promulgado por el general Pinochet. De este modo, la cueca del Chile central y la de campeonato, junto con la cueca, cachimbo y huaino de autor, propuesto desde el centro del país, se instauró en el imaginario colectivo nacional como la música tradicional de la región.

14 Construidos en época colonial, los socavones son túneles que recogen y canalizan el agua subterránea hacia las cochas, estanques de acumulación y redistribución de las aguas, la que se efectúa por medio de canales de superficie. 
15 Este espacio, que aún se constituye como prolongación del patio de la vivienda, se creó a mediados del siglo XIX, cuando la incrementación de la explotación del salitre propiciaba una masiva migración masculina hacia los nuevos centros de trabajo. En este contexto, la organización del trabajo campesino quedó en manos de las mujeres, que, entre otras cosas, modificaron la estética de las haciendas (Daponte 2004:78).

16 A este propósito y para el caso de Chile, Martínez y Palmiero afirman que: "Dos factores se encargarán de llenar los oídos de la burguesía chilena con los cantos populares; el primero será la existencia de locales públicos frecuentados por distintas clases sociales y el segundo la relación vital que mantenía la clase pudiente, sobre todo los terratenientes, con la realidad provincial o campesina" (2000:704).

17 Del baile y tierra cantado se conservan en la región solo dos; Las Heladas de Mamiña y el San Miguel o San Miguelito que se interpretaba en algunos salones de Pica.

18 Queremos destacar que, en los convites, los instrumentos musicales utilizados son aquellos de origen europeo y no corresponden a un posible horizonte andino; sin embargo, en otras manifestaciones culturales de los mismos pueblos, como las fiestas religiosas, se utilizan los tradicionales instrumentos de vientos que son comunes al área centro andina y a las poblaciones aimaras: quenas, tarkas y zampoñas. Acerca de la difusión de estos instrumentos musicales en la región ver el artículo de Díaz, Mondaca y otros (2000); del origen y la presencia de estos instrumentos musicales en los relatos de los cronistas coloniales ver Focacci y Pizarro (2000).

19 "Recuerda doña Irma [Zegarra], que a principios de este siglo (1900) existían 25 pianos distribuidos en casas de las familias más pudientes" (Loyola 1994:37). Los pianos llegaban en barco al puerto de Iquique y, según Enrique Luza (1994 comunicación personal), eran transportados en "mulas pianeras" hasta los pueblos del interior; la llegada de un instrumento al oasis generaba mucha expectativa y se convertía en una verdadera fiesta.

20 El músico Enrique Luza escribía, recordando a los carnavales, que el baile terminaba con La Republicana. Esta es la única referencia encontrada respecto de este baile. 1996:79. En otras comunicaciones se habla siempre del cachimbo.

21 La Fantasía Navideña de Enrique Luza es una suite para piano basada en algunos villancicos típicos de las adoraciones al Niño Dios que se realizan frente a los pesebres para el 6 de enero.

22 El parabién es un espacio comunitario de celebración y recreación que se utiliza principalmente para la fiesta patronal y el carnaval. En cuanto al nombre del cachimbo, seguramente deriva de la asociación de este baile con la población negra de la región. Algunos vecinos de Pica, como Roberto Gómez (comunicación personal 1994) o Enrique Luza (comunicación personal 1994), asociaban esta palabra también a los esclavos negros orgullosos, de elevada estatura, que servían de mayordomos en las casas aristocráticas, refiriéndose a ellos como "negro acachimbao" o "negro cachimbo".

23 A finales de la década de 1960, la folclorista Margot Loyola registró y transcribió tres melodías en el pueblo de Tarapacá y sus alrededores (1994:110-123).

24 Esta melodía se hizo conocida en todo Chile después que el folclorista Calatambo Albarracín le creara un texto para cantarla y presentarla en distintos festivales. La versión de Albarracín fue tan exitosa que los compositores más destacados del movimiento llamado del "neofolclor", como Raúl de Ramón, Rolando Alarcón y Vicente Bianchi, entre otros, se inspiraron en esta y compusieron nuevos cachimbos; convirtiendo esta danza en un importante género de raíz folclórica, a nivel nacional. Este tipo de cachimbo fue practicado principalmente en las oficinas salitreras, no así en los pueblos y oasis en que no tuvo una gran difusión.

25 El cachimbo de autor y la cueca "nortina", como se le llamó a este formato moderno de cueca, entraron a formar parte del "cuadro del norte" en los espectáculos presentados por los conjuntos folclóricos a lo largo de todo el país. Este fenómeno contribuyó al proceso de cristalización de parte del repertorio musical de la región.

26 El músico Julio Arroyo era conocido por sus interpretaciones de yaravíes en violín. La guitarra arequipeña, con sus arpegiados y punteados, nunca llegó a la región. 